\title{
Adult Nodular Lymphocyte Predominant Hodgkin Lymphoma
}

National Cancer Institute

\section{Source}

National Cancer Institute. Adult Nodular Lymphocyte Predominant Hodgkin Lymphoma. NCl Thesaurus. Code C7942.

A nodular lymphocyte predominant Hodgkin lymphoma occurring in adults. 